\title{
FOURNIER'S GANGRENE OF PENIS: A RARE CASE REPORT
}

Jagadeeshwar $^{1}$, G. Ravichandar ${ }^{2}$, B. Santosh ${ }^{3}$, N. Srinivas ${ }^{4}$, K. V. Narendra ${ }^{5}$

\section{HOW TO CITE THIS ARTICLE:}

Jagadeeshwar, G. Ravichandar, B. Santosh, N. Srinivas, K. V. Narendra. "Fournier's Gangrene of Penis: A Rare Case Report". Journal of Evolution of Medical and Dental Sciences 2014; Vol. 3, Issue 74, December 29; Page: 15625-15628, DOI: $10.14260 /$ jemds/2014/4111

ABSTRACT: Fournier's gangrene is a form of Necrotizing fascitis occurring about the Male genitalia i.e., Scrotum, Penis and occasionally extending up to anterior abdominal wall. The usual causative organisms are mixed aerobic and anaerobic organisms due to Periurethral, groin or anorectal sepsis which may be some times trivial. Condition is best treated with immediate hospitalization early parenteral broad spectrum antibiotics and timely debridement of involved tissues followed by skin grafting of raw areas. Fournier's gangrene involving only Penis is very rare and is being reported.

KEYWORDS: Fournier's gangrene of penis, Necrotizing fasciitis, Wound debridement, Skin grafting.

INTRODUCTION: Fournier's gangrene is a form of Necrotizing fascitis occurring about the male genitalia. ${ }^{1}$ It generally involves Scrotum and Penis with occasional extension up to the abdominal wall. Only few cases of Fournier's gangrene of Penis have been reported.2,3 We report one such case in which only Penis is involved without involvement of Scrotum or Abdominal wall.

CASE REPORT: A 35yr. old married man presented with swelling and blackish discolouration of Penis with Fever and local pain of 3 days duration. There was no history of trauma or instrumentation or any sepsis in the genito-perineal area. Patient had history of Prepucial abrasions during sexual intercourse 5 days back. Two days after which he developed severe swelling of Penis with brownish-black discolouration with small bullae. Patient is not diabetic.

On general examination, patient had fever and vital signs showed tachycardia with normal Blood pressure.

Local examination revealed foul smelling blackish discolouration of entire Penile Skin upto Peno-Scrotal junction without any clear line of demarcation with almost sloughed Penile Skin over the Ventral aspect. (Figures 1,2)

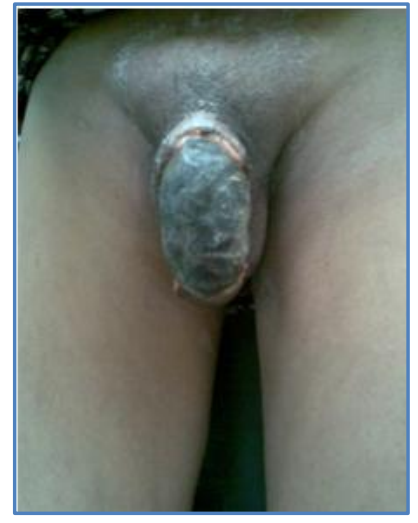

Fig. 1

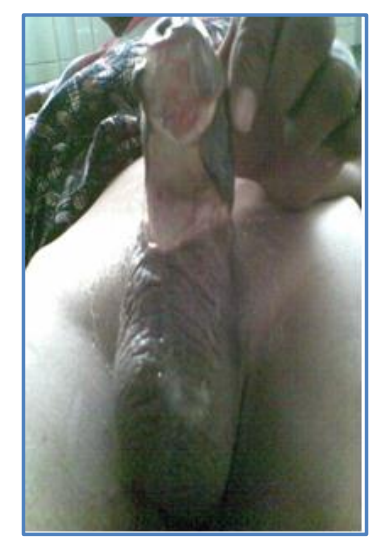

Fig. 2 


\section{CASE REPORT}

Figures 1 and 2: Blackish discoloured penile skin with ventral sloughing. Rest of genito-Perineal area and per rectal examination was normal.

Complete blood picture revealed Leucocytosis and Neutrophilia with raised ESR, and normal $\mathrm{Hb} \%$. Complete Urine examination was within normal limits. Random blood sugar, blood urea and Serum Creatinine were normal. USG of Abdomen and Pelvis was normal.

Patient was admitted and was started on Ceftrioxone, Amikacin and Metronidazole. Parenterally. Emergency slough excision of entire Penile Skin done.

Culture of Discharge from Penile skin showed E.coli, Streptococcus pyogenes, streptococcus faecalis organisms sensitive to Ceftrioxone, Aztreonam, Cefoperazone, Amikacin, After 2 times of debridement and regular dressing of penile raw area, when the bed is having good granulations, Unexpanded Meshed split thickness skin grafting done taken from anterior thigh. (Figures 3, 4)

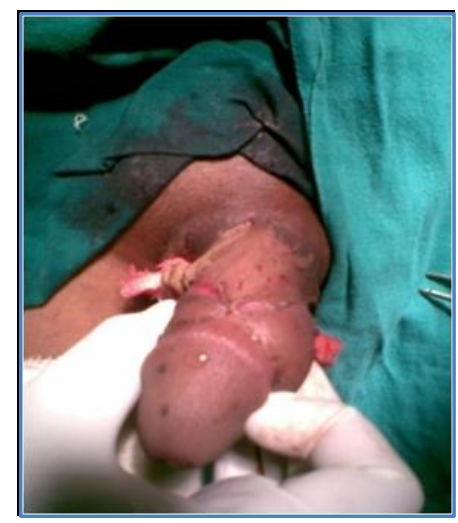

Fig. 3

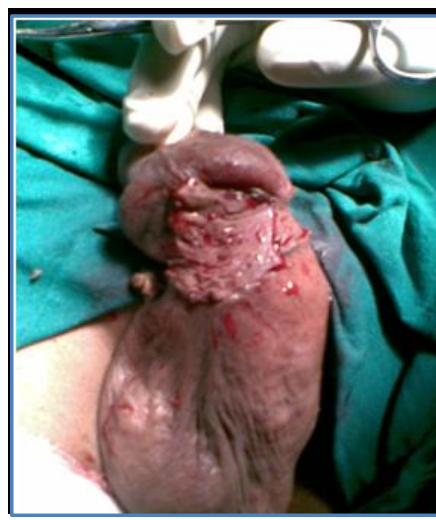

Fig. 4

Figures 3 and 4: split thickness skin graft being applied over penis.

Post-operative dressing revealed total take up of graft.

At 3 months follow up the patient is asymptomatic with good cosmesis of Penis (Figure 5) The patient is having normal erectile and ejaculatory function.

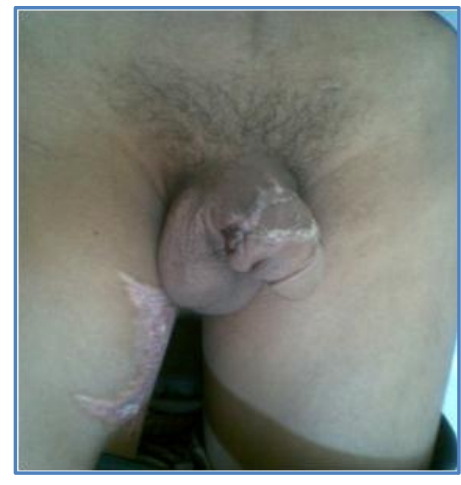

Fig. 5

Figure 5: 3 months follow up photograph of penis. 


\section{CASE REPORT}

DISCUSSION: Fournier's gangrene is a rare fulminant, though generally localized disease of Scrotum and Penis with occasional extension up the abdominal wall.2,3

Although originally reported as idiopathic, genital gangrene of healthy young patients, it involves wider age range including older patients. ${ }^{1}$

The disease is a necrotizing fascitis of infective origin and always has a portal of entry of infective organisms even though it may be so trivial as to be undetected.

The commonest portals of entry of infection are peri urethral sepsis, groin wounds, rectal infections, prostatic sepsis and trauma ${ }^{4}$

The infecting organisms comprise both aerobic and anaerobic organisms, such as E-Coli, Streptococcus Pyogenes, Pseudomonas Aeruginosa, Klebsiella Pneumoniae, Proteus Mirabilis, Bacteroides fragilis, and Anaerobic Streptococcus 4, 5

Even though Fournier's gangrene is caused by Polymicrobial virulent organisms, rarely it can be caused by low virulent organisms like Lactobacillus gasseri as reported by Tleyjeh et al ${ }^{6}$

Bernstein SM et al ${ }^{2}$ and Mireku Buateng AO et al ${ }^{7}$ have reported cases with Fournier's gangrene of Penis and Penile ulcerations as sequelae of abnormal sexual practices and parenteral drug abuse.

Literature review reveals two cases of Penile gangrene due to ischemic small vessel disease involving the entire Penile shaft reported by Frydenberg ${ }^{8}$ which is a separate entity from Fournier's gangrene.

Treatment of Fournier's gangrene includes immediate hospitalization, broad spectrum parenteral antibiotics and timely surgical debridement.2,3

Split thickness skin grafting is used for reconstruction of Penile skin loss 4

Black PC et al ${ }^{9}$ had used Meshed unexpanded split thickness skin graft for Penile skin loss in nine patients which yielded satisfactory functional and cosmetic outcomes.

CONCLUSION: Fournier's gangrene involving only the Penis as seen in our case is very rare. Only few cases are reported in literature. Probable cause is trivial prepucial trauma in our case.

Early broad spectrum antibiotics, covering aerobic and anaerobic organisms and timely surgical debridement followed by split thickness skin grafting gives very good results as seen in our case.

\section{REFERENCES:}

1. Anthony J. Schaffer, Edward M. Schaffer Campbell - Walsh Urology $9^{\text {th }}$ edition, Infection of urinary tract; 301-2.

2. Bernstein SM, Celano T, Sibulkin D. Fournier's gangrene of penis. South Med J 1976; 69: 1242-4.

3. Schneider P R, Russell RC, Zook E G. Fournier's Gangrene of Penis: A Report of two cases Ann Plast surg 1986; 17: 87-90.

4. Leo Francis Tauro, Roshan M., B.S Satish Rao, Ravikrishnan J., Leo T. Menezes. Fournier's gangrene of the penis, Indian J plast. Surg July-Dec 2005; 38: 154 - 156.

5. Efem SE. The features and aetiology of Fournier's gangrene. Postgrad Med J 1994; 70: 568-71.

6. Tleyjeh IM, Routh J, Qutub MO, Lischer G, Liang KV, Baddour LM. Lactobacillus gasseri causing Fournier's gangrene. Scand J Infect Dis 2004; 36: 501-3. 


\section{CASE REPORT}

7. Mireku-Boateng AO, Nwokeji C. Sequalae of parenteral drug abuse involving the external genitalia. Urol Int 2004; 73: 302-4.

8. Frydenberg M. Penile gangrene: a separate entity from Fournier's syndrome? Br J Urol 1998; 61: 523-3.

9. Black PC, Friedrich JB, Engrav LH, Wessells H. Meshed unexpanded split-thickness skin grafting for reconstruction of penile skin loss. J Urol 2004; 172: 976-9.

\section{AUTHORS:}

1. Jagadeeshwar

2. G. Ravichandar

3. B. Santosh

4. N. Srinivas

5. K. V. Narendra

\section{PARTICULARS OF CONTRIBUTORS:}

1. HOD and Professor, Department of Urology, Gandhi Medical College, Secundrabad.

2. Assistant Professor, Department of Urology, Gandhi Medical College, Secundrabad.

3. Assistant Professor, Department of Urology, Osmania Medical College, Secundrabad.
4. Senior Consultant, Department of Urology, care hospital, Secundrabad.

5. Post Graduate, Department of Urology, Gandhi Medical College, Secundrabad.

\section{NAME ADDRESS EMAIL ID OF THE CORRESPONDING AUTHOR:}

Dr. T. Jagadeeshwar, Professor and HOD, Department of Urology, Gandhi Medical College, Secunderabad - 500002. E-mail: kesana99@gmail.com

Date of Submission: 20/11/2014. Date of Peer Review: 21/11/2014. Date of Acceptance: 18/12/2014. Date of Publishing: 29/12/2014. 